\title{
Produção de mini-tubérculos de batata-semente em função de doses de nitrogênio aplicadas ao substrato
}

\author{
Paulo CR Fontes ${ }^{1 ; 3}$; José D Sampaio Júnior ${ }^{1}$; Marialva A Moreira ${ }^{1 ; 3}$; Marcelo de A Guimarães³; Mário \\ Puiatti $^{1}$; Elisonete RG Lani ${ }^{1}$ \\ ${ }^{1}$ UFV, Depto. Fitotecnia, 36571-000 Viçosa-MG; ${ }^{2}$ UFV, Depto. Biologia Vegetal; ${ }^{3 B}$ Bolsista CNPq; pacerefo@ufv.br; mguimara@hotmail.com
}

\begin{abstract}
RESUMO
O objetivo do trabalho foi avaliar o efeito de doses de nitrogênio aplicadas em substrato sobre a produção de mini-tubérculos de batata-semente (Solanum tuberosum L.), cultivar Monalisa, a partir de plântulas advindas de cultura de tecido. O experimento foi realizado em ambiente protegido, no Depo. de Fitotecnia da UFV. Duas plântulas micropropagadas por cultura de tecido foram plantadas em vaso de 3 L contendo substrato. Foram avaliadas cinco doses de nitrogênio: 0; 50; 100; 200 e $400 \mathrm{mg} \mathrm{kg}^{-1}$ de $\mathrm{N}$, na forma de $\mathrm{NH}_{4} \mathrm{NO}_{3}$, dispostas em blocos ao acaso e cinco repetições. O índice SPAD, medido na quarta folha (LQ), aumentou com o aumento da dose de $\mathrm{N}$ e diminuiu com a idade da planta. O teor de $\mathrm{N}_{-} \mathrm{NO}_{3}^{-}$na matéria seca da $\mathrm{LQ}$, associado à

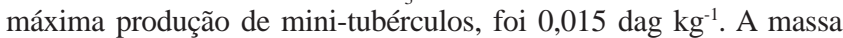
seca dos mini-tubérculos, massa seca total da planta e produção de mini-tubérculos foram de, no máximo, 25,74; 31,93 e 138,8 g vaso-1, respectivamente, com a dose de $0 \mathrm{mg} \mathrm{kg}^{-1}$ de $\mathrm{N}$.
\end{abstract}

Palavras-chave: Solanum tuberosum, adubação, ambiente protegido, cultivo protegido.

\begin{abstract}
Minituber potato seed yield as a result of nitrogen rates applied in the substrate

The effects of nitrogen rates on minituber seed potato (Solanum tuberosum L.) was evaluated on cv. Monalisa, propagated in vitro. The experiment was conducted in a greenhouse. Two tissue culture propagated potato plantlets were planted in $3 \mathrm{~L}$ pots with substrate. Five $\mathrm{N}$ rates, 0 ; 50; 100; 200 and $400 \mathrm{mg} \mathrm{kg}^{-1}$ of $\mathrm{N}$, as $\mathrm{NH}_{4} \mathrm{NO}_{3}$, were evaluated in randomized complete block design and five replications. The SPAD index in the fourth leaf (LQ) increased with the increase of $\mathrm{N}$ rates and decreased with the plant age. $\mathrm{N}^{-N^{-}}{ }_{3}^{-}$content in the LQ dry matter, associated with the maximum minitubers yield was 0.015 dag $\mathrm{kg}^{-1}$. The maximum minituber dry matter, the maximum plant dry matter and maximum minituber yield were 25.74; 31.93 and $138.8 \mathrm{~g}$ pot $^{-1}$, respectively, with $0 \mathrm{mg} \mathrm{kg}^{-1} \mathrm{of} \mathrm{N}$.
\end{abstract}

Keywords: Solanum tuberosum, fertilization, unheated greenhouse.

(Recebido para publicação em 8 de maio de 2007; aceito em 20 de fevereiro de 2008)

\begin{abstract}
A batata é propagada assexuadamente por "tubérculossemente”. A batata-semente constitui-se no componente que mais onera o custo de produção, variando de 25 a 40\% (Assis, 1999; Nagano, 1999). No Brasil, vários fatores têm contribuído para que, nas últimas décadas, tenha crescido a produção de batatas-semente básica, registrada e certificada. Incentivos governamentais, preço alto da semente importada, melhoria da tecnologia aplicada pelos produtores, instalação de laboratórios de cultura de tecidos onde se pode efetuar a limpeza de vírus e a propagação rápida de plântulas in vitro (Assis, 1999).
\end{abstract}

A técnica de cultura de tecidos tem sido usada para produzir batata-semente pré-básica utilizando-se, normalmente, como propágulo, uma seção pequena de caule contendo uma gema e a folha adjacente (segmento nodal). Esse propágulo dá origem à plântula e, posteriormente, ao microtubérculo. As plântulas ou microtubérculos produzi- dos são utilizados para a produção de tubérculo semente básica. Assim, segundo Daniels et al. (2002) a propagação in vitro da batata pelo cultivo de segmentos nodais está estabelecida como método de multiplicar rapidamente cultivares novas ou já existentes em condições livres de patógenos. Os microtubérculos podem ser utilizados durante os estágios de certificação para a produção de tubérculo-semente (Donnelly et al., 2003) e constituem-se em solução para países que necessitam de tubérculos-semente de qualidade, devido ao aumento de novas áreas de plantio com batata, como a China, Índia, e outras partes da Ásia (Maldonado et al., 1998).

Normalmente, as plântulas advindas da cultura de tecidos são plantadas em vaso contendo substrato visando à produção de semente básica de batata (Grigoriadou \& Leventakis, 1999). O substrato deve permitir adequadas aeração, infiltração e armazenamento de água, além da isenção de patógenos e de uniformidades na disponibilidade de nutrientes. Normalmente, a quantidade de nutrientes presente na maioria dos substratos é baixa ou nula, sendo necessária a adição de fertilizantes para o desenvolvimento e produção da planta.

Dentre os nutrientes limitantes nos substratos, o nitrogênio (N) merece destaque. Quase sempre é necessário aplicar fertilizante nitrogenado em dose adequada para a obtenção de plantas com número elevado de tubérculos e de tamanho apropriado para a utilização como semente básica. O $\mathrm{N}$ influencia tanto o número quanto o peso dos tubérculos produzidos por planta (Errebhi et al., 1998; Meyer \& Marcum, 1998). Dependendo do teor existente no solo, dose sub-ótima de $\mathrm{N}$ reduz a produtividade, enquanto que dose excessiva atrasa o início da tuberização, prolonga o ciclo da cultura e reduz a produtividade (Oparka et al., 1987; Gil, 2002).

Recomendação de dose de $\mathrm{N}$ para o plantio no campo é abundante na literatura. Contudo, estudos visando à reco- 
mendação de dose de $\mathrm{N}$ a ser aplicada ao substrato, tendo como material propagativo plântulas recém saídas do tubo de ensaio são escassos. Objetivouse com o presente trabalho avaliar o efeito de doses de nitrogênio aplicadas ao substrato sobre a produção de mini-tubérculos semente de batata, ao serem plantadas plântulas advindas de cultura de tecidos.

\section{MATERIAL E MÉTODOS}

Foram utilizadas plântulas de batata da cultivar Monalisa oriundas de cultura de tecidos e obtidas em duas etapas: a primeira, a micropropagação foi conduzida no Laboratório de Cultura de Tecidos da UFV. Esta fase iniciou-se no dia 04/02/04 utilizando-se plântulas provenientes de tubo de ensaio e isentas de vírus (denominadas “plântulas mães”), as quais haviam sido multiplicadas por microestacas. Estas microestacas viáveis foram obtidas após o seccionamento das "plântulas mães" e cultivadas em tubos de ensaio de 25X150 mm com $10 \mathrm{~mL}$ de meio de cultura. Foi utilizado o meio padrão de sais M \& S (Murashige \& Skoog, 1962), com vitaminas, $20 \mathrm{~g} \mathrm{~L}^{-1}$ de sacarose, $5 \mathrm{~g}$ $\mathrm{L}^{-1}$ de ágar e 0,0133 $\mathrm{g} \mathrm{L}^{-1}$ de alar 64\% (daminozide), sendo o $\mathrm{pH}$ do meio ajustado para 5,7. As vitaminas adicionadas foram: $2 \mathrm{mg} \mathrm{L}{ }^{-1}$ de glicina; $100 \mathrm{mg} \mathrm{L}^{-1}$ de i-inositol; 0,50 $\mathrm{mg} \mathrm{L}^{-1}$ de ácido nicotínico; 0,50 $\mathrm{mg} \mathrm{L}^{-1}$ de piridoxina e 0,10 $\mathrm{mg} \mathrm{L}^{-1}$ de tiamina. Cada tubo de ensaio contendo uma microestaca foi fechado com tampa de policarbonato e selado com filme plástico sendo colocado, logo em seguida, em câmara de crescimento, a $26^{\circ} \mathrm{C}$, umidade relativa de $40 \%$ e fotoperíodo de 16 h supridos por lâmpadas fluorescentes com densidade de fluxo fotossintético de $30 \mu \mathrm{mol}$ $\mathrm{m}^{-2} \mathrm{~s}^{-1}$. Os tubos permaneceram nesse ambiente por 29 dias. A segunda etapa, a aclimatação foi realizada no Laboratório de Fisiologia Vegetal da UFV, em fotoperíodo de $16 \mathrm{~h}$, suplementado por lâmpadas fluorescentes, com densidade de fluxo fotossintético de $30 \mu \mathrm{mol} \mathrm{m} \mathrm{m}^{-2}$ $\mathrm{s}^{-1}$. Esta fase iniciou-se quando as plântulas foram retiradas dos tubos de ensaio e tiveram as raízes lavadas em água corrente para eliminar o restante do meio de cultura. Em seguida, as plântulas foram transferidas para copos plásticos descartáveis contendo, aproximadamente, $100 \mathrm{~mL}$ de substrato comercial BioPlant ${ }^{\circledR}$, levemente umedecido. Em cada copo foi plantada uma plântula. Em seguida, o copo foi envolto por saco plástico translúcido, de $18 \times 12 \mathrm{~cm}$, de altura e diâmetro, respectivamente, preso na base do copo por elástico de borracha, a fim de se criar uma campânula para evitar a redução excessiva da umidade, tanto do substrato quanto do ar.

Após 20 dias do inicio da aclimatação, cada plântula foi retirada do copo plástico, juntamente com o substrato, e plantada em vaso de $3 \mathrm{~L}$ contendo substrato, nos diversos tratamentos de doses de $\mathrm{N}$. O pH, a condutividade elétrica (extrato 2:1) e o teor de nitrogênio total do substrato foram 5,8 e 2,2 mS cm-1, 0,8 dag kg-1, respectivamente. Em todos os tratamentos, o substrato foi uniformemente adubado com macro e micronutrientes, superfosfato simples: $3.380 \mathrm{mg} \mathrm{L}^{-1}$, sulfato de magnésio: $560 \mathrm{mg} \mathrm{L}^{-1}$, cloreto de potássio: $200 \mathrm{mg} \mathrm{L}^{-1}$, ácido bórico: 2,5 mg L $\mathrm{m}^{-1}$, sulfato de zinco: $2,5 \mathrm{mg} \mathrm{L}^{-1}$ , sulfato de cobre: $2,5 \mathrm{mg} \mathrm{L}^{-1}$, molibdato de amônio: 0,25 $\mathrm{mg} \mathrm{L}^{-1}$, sulfato ferroso: 2,5 $\mathrm{mg} \mathrm{L}^{-1}$, sulfato manganoso: $2,5 \mathrm{mg}$ $\mathrm{L}^{-1}$.

O experimento foi realizado com duas plântulas por vaso, em casa de vegetação do Departamento de Fitotecnia da UFV. Foram avaliadas cinco doses de $\mathrm{N}$ aplicadas ao substrato: 0 ; 50; 100; 200 e $400 \mathrm{mg} \mathrm{dm}^{-3}$ de $\mathrm{N}$, na forma de $\mathrm{NH}_{4} \mathrm{NO}_{3}$. Cada dose foi dividida em 30 partes e cada uma foi diluída em 200 $\mathrm{mL}$ de água que foram aplicados em cada vaso, diariamente, a partir de 23 dias após o plantio (DAP). Os vasos foram irrigados diariamente conforme a necessidade, determinada pelo tato. A amontoa foi realizada aos 34 dias após o plantio (DAP) adicionando-se mais substrato na parte superior do vaso. Os caules das plantas foram tutorados verticalmente com barbante.

Após 98 dias do plantio, as plantas foram colhidas e os mini-tubérculos classificados em tipos, V (16 a 23 mm), VI (13 a $16 \mathrm{~mm})$, VII (10 a $13 \mathrm{~mm}$ ) e VIII (<10 mm), de acordo com IMA (2003). Outras características avaliadas foram:
1) Índice SPAD, medido com o clorofilômetro SPAD-502 (Soil-Plant Analysis Development SPAD-Section), da Minolta Câmera Co., Ltda., Japan. A primeira determinação do índice SPAD foi denominada SPAD 1 (S1) sendo realizada aos 37 dias após o plantio (DAP). A partir da primeira medição foram realizadas medições, semanalmente, durante 5 semanas aos 44 (S2), 51 (S3), 58 (S4), 65 (S5) e 72 (S6) dias após o plantio. As leituras do índice SPAD foram realizadas no período matinal, na quarta folha a partir do ápice (LQ). Nas mesmas épocas, também foram realizadas leituras do índice SPAD em uma folha fixa, a segunda folha a partir da base da planta (LF). Aos 79 DAP foi medido o índice SPAD (S7) na LQ imediatamente antes da mesma ser destacada de cada planta útil para a posterior análise do teor de N-NOÉ ${ }_{3}$ na massa seca (MS).

2) Altura da planta, realizada a partir do nível do substrato até a região apical da planta; para plantas com mais de uma haste foi determinada a média da altura destas hastes. As medições foram efetuadas semanalmente, aos 51, 58 e 72 DAP.

3) Número de folhas aos 44 DAP.

4) Teor de ${\mathrm{N}-\mathrm{NO}_{3}^{-}}_{3}$ na massa seca da LQ coletada aos 79 DAP segundo a metodologia de Cataldo et al., (1975).

5) Massa seca da quarta folha (MSQF), de folhas (MSF), caules (MSC), raízes (MSR), mini-tubérculos (MSMT), total (MST) e classificação dos tubérculos, realizadas aos 98 DAP.

Os dados foram submetidos às análises de variância e regressão. Os modelos de regressão foram escolhidos baseados na significância dos coeficientes de regressão utilizando o teste $\mathrm{F}$, com o nível de 5 e 1 \% de probabilidade, na lógica biológica e no coeficiente de determinação. Foram avaliados os modelos linear, quadrático, cúbico, linear raiz, quadrático raiz e cúbico raiz; quando possível, foi calculado o ponto de máximo, por derivação.

\section{RESULTADOS E DISCUSSÃO}

Não houve efeito de dose de N sobre as seguintes variáveis: leituras obtidas com o clorofilômetro SPAD 502 na quarta folha a partir do ápice (LQ) aos 
Tabela 1. Equações ajustadas para o índice SPAD medido na quarta folha a partir do ápice (LQ), aos 51 (LQS3), 58 (LQS4), 65 (LQS5), 72 (LQS6) e 79 dias após o plantio (LQS7), em função das doses de nitrogênio (N) aplicadas ao substrato. Viçosa, UFV, 2004.

\begin{tabular}{llc}
\hline Variáveis & Equações ajustadas & $\mathbf{r}^{2}$ \\
\hline QS3 & SPAD $=34,129+0,09 \mathrm{~N}-0,0002 \mathrm{~N}^{2}$ & $0,98^{* *}$ \\
LQS4 & SPAD $=30,46+0,0513 \mathrm{~N}-0,00009 \mathrm{~N}^{2}$ & $0,99 * *$ \\
LQS5 & SPAD $=30,459+0,0167 \mathrm{~N}$ & $0,79 * *$ \\
LQS6 & SPAD $=19,645+0,0853 \mathrm{~N}-0,0002 \mathrm{~N}^{2}$ & $0,89 * *$ \\
LQS7 & SPAD $=24,168+0,040 \mathrm{~N}-0,000068 \mathrm{~N}^{2}$ & $0,644^{* *}$ \\
\hline
\end{tabular}

**equação significativa a $1 \%$ de probabilidade pelo teste "F".

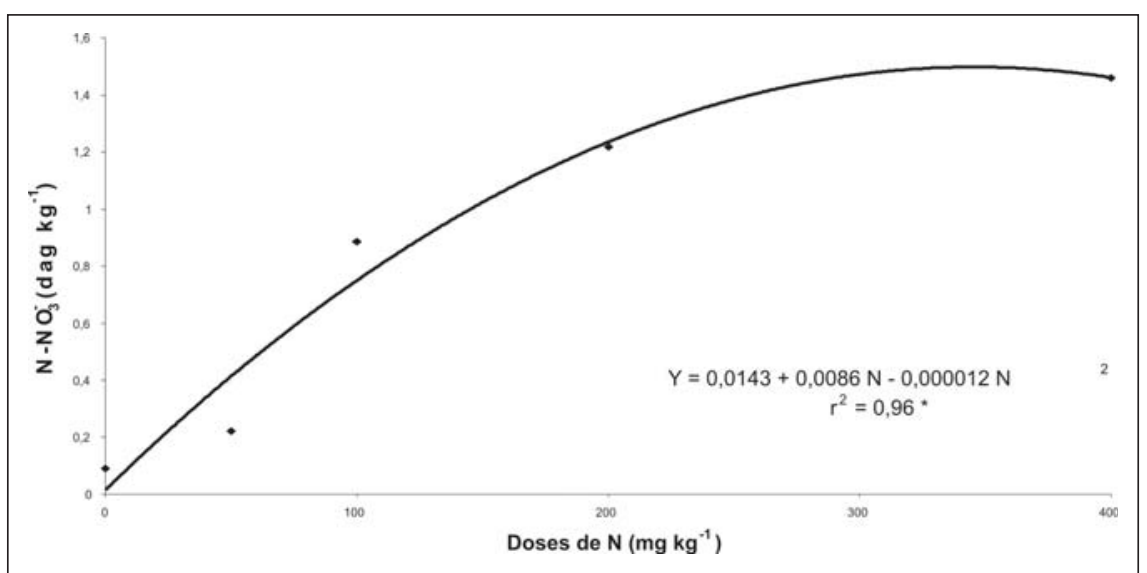

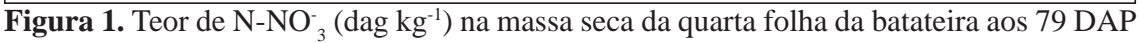
(LQS7) em função de doses de nitrogênio aplicadas ao substrato. Viçosa, UFV, 2004.

37 DAP (LQS1) e 44 DAP (LQS2) e na folha fixa (LF) aos 37 DAP (LFS1), 51 DAP (LFS3) e 58 DAP (LFS4). Isto é, os índices SPAD avaliados em LQS1, LQS2, LFS1, LFS3 e LFS4 não sofreram influência das doses de $\mathrm{N}$ aplicadas ao substrato, variando as médias de 41,46 a 30,02 . Isto pode ter ocorrido devido às plântulas advindas de cultura de tecido e o substrato terem quantidade de $\mathrm{N}$ capaz de suprir a planta na fase inicial de crescimento.

Por outro lado, houve efeito positivo de doses de N sobre as variáveis: leitura obtida com o clorofilômetro SPAD 502 na quarta folha a partir do ápice (LQ) aos 51 DAP (LQS3), 58 DAP (LQS4), 65 DAP (LQS5), 72 DAP (LQS6) e 79 DAP (LQS7), e leitura na folha fixa (LF) aos 44 DAP (LFS2), 65 DAP (LFS5) e 72 DAP (LFS6).

Aumento em SPAD significa aumento na intensidade da cor verde da planta e, segundo Fontes (2001), o índice SPAD mede de forma indireta o teor de clorofila, indicando o estado de nitrogênio da planta. A clorofila é o pigmento envolvido na fotossíntese e, cor- relações positivas entre a taxa fotossintética e os teores de nitrogênio da planta têm sido observadas por diversos autores (Keulen \& Stol, 1991; Makino et al., 1994). Vos \& Bom (1993) também verificaram correlação positiva entre o teor da clorofila na planta e a adição do $\mathrm{N}$ na cultura da batata, indicando que o teor de clorofila na planta está relacionado com o estado nutricional nitrogenado (Minotti et al., 1994). Piekielek \& Fox (1992) e Argenta et al. (2001) observaram que os valores SPAD em milho estiveram correlacionados com a quantidade de $\mathrm{N}$ adicionada para a obtenção da máxima produção e com a produção de grãos. Rodrigues et al. (2000) obtiveram aumento do índice SPAD medido na quarta folha completamente expandida da batata cultivar Monalisa aos 20 DAE com o incremento da dose de $\mathrm{N}$.

Os modelos que melhor descreveram o efeito de dose de $\mathrm{N}$ sobre as leituras SPAD na LQ estão apresentados na Tabela 1. O índice SPAD na LQ associado à dose de $\mathrm{N}$ que propiciou a máxima produção de tubérculos, avaliado aos 37 DAP, foi 41,46. Malavolta et al. (1997) citam a faixa de 49 a 56 como adequada para o índice SPAD na quarta ou quinta folha mais nova totalmente expandida a partir do ápice, amostrada um mês depois do plantio em condições de campo. Rodrigues et al. (2000), em solução nutritiva, determinaram o nível crítico do índice SPAD de 39,6 na quarta folha jovem completamente expandida da cultivar Monalisa, de 57 dias de idade. Gil (2001) obteve o valor de 45,30 unidades SPAD na quarta folha completamente expandida a partir do ápice aos 20 dias após a emergência (DAE), associado à maior produção de tubérculos.

Os valores dos índices SPAD na folha fixa (LF) variaram em função das doses de $\mathrm{N}$ aplicadas no substrato. Porém, em LF os valores de SPAD foram inferiores quando comparados aos da LQ. Isso pode ser explicado pela remobilização do nitrogênio na planta, da folha mais velha (LF) para as mais novas (LQ). Esse fato indica a necessidade de padronizar a folha a ser usada para efeito de diagnóstico, conforme mencionado por Fontes (2001).

Houve efeito linear decrescente da dose de $\mathrm{N}$ sobre a altura das plantas medidas aos 51 (A1), 58 (A2) e 72 (A3) dias após o plantio (DAP). No meio de cultivo há adição de diversos componentes nitrogenados entre os quais hormônios e $\mathrm{N}$ que podem ter influenciado a resposta da planta à adição de N. Assim, as doses aplicadas ao substrato foram excessivas para o crescimento da planta em altura.

Em avaliação realizada aos 44 DAP, não houve efeito de doses de $\mathrm{N}$ sobre o número de folhas (NF) onde o valor médio foi de 42,6 folhas planta ${ }^{-1}$. Isto indica que a disponibilidade de $\mathrm{N}$ no substrato não alterou o rítimo plastocrômico das plantas. De forma contrária, Gil (2001) obteve em campo, com o incremento da dose de $\mathrm{N}$ em préplantio, aumento linear do NF da batateira. Segundo Biemond \& Vos (1992) e Vos \& Putten (1998), o número total de folhas é influenciado pela disponibilidade de N. A taxa de surgimento de novas folhas aumenta acentuadamente com o aumento da formação dos ramos devido a altos níveis de nitrogênio (Oliveira, 2000). 
Em determinação única realizada aos 79 DAP (LQS7), houve efeito de doses de $\mathrm{N}$ sobre o teor de $\mathrm{N}^{-\mathrm{NO}_{3}^{-}}$da massa seca da quarta folha (LQ) da batateira, sendo a relação descrita pelo modelo quadrático (Figura 1). O valor máximo desta variável foi 1,5 dag $\mathrm{kg}^{-1}$ com a dose de $358,3 \mathrm{mg} \mathrm{kg}^{-1}$ de $\mathrm{N}$. Acréscimos nas concentrações de $\mathrm{N}$ $\mathrm{NO}_{3}^{-}$na folha têm sido detectados com o aumento da quantidade de nitrogênio aplicado. Os aumentos tendem a atingir variações pronunciadas, as quais decrescem à medida que aumenta a quantidade do fertilizante aplicado (Asfary et al., 1983; Maclean, 1981; Roberts et al., 1982; White \& Sanderson, 1983).

Para a dose zero de N, que propiciou a maior produção de tubérculos, o valor do teor de $\mathrm{N}^{-} \mathrm{NO}_{3}^{-}$na LQS7 foi 0,0143 dag $\mathrm{kg}^{-1}$, isto é, o acúmulo de $\mathrm{NO}_{3}^{-}$nesta folha foi mínimo. Gil (2001) mostrou que o teor de $\mathrm{N}^{-\mathrm{NO}_{3}^{-}}$na massa seca do pecíolo da quarta folha da batata no campo aumentou de maneira quadrática, com o incremento das doses de $\mathrm{N}$ em pré-plantio, encontrando valor de 1,52 dag $\mathrm{kg}^{-1}$ para a dose de $\mathrm{N}$ que propiciou a maior produção de tubérculos comerciais medida aos 20 DAE, resultado esse semelhante aos obtidos em outros trabalhos (Porter \& Sisson, 1991; Porter \& Sisson, 1993), nos quais também verificaram aumento do teor de $\mathrm{N}_{-} \mathrm{NOE}_{3}$ na massa seca do pecíolo da quarta folha com o aumento da dose de nitrogênio.

Não houve efeito de doses de N sobre as massas secas da quarta folha (MSQF), folhas (MSF), caules (MSC) e raízes (MSR) avaliados aos 98 DAP. Esses índices não refletiram a adição diferenciada de $\mathrm{N}$, não sendo úteis como ferramenta de diagnóstico. Gil (2001) encontrou, em condições de campo, aumento linear na MSF da batata com a aplicação de $\mathrm{N}$ e Biemond \& Vos (1992) obtiveram aumento da massa seca do caule com aumento da dose de nitrogênio.

Houve efeito negativo de doses de $\mathrm{N}$ sobre a massa seca dos tubérculos (MSTB). O aumento na dose de N propiciou redução linear na MSTB, com a produção de $25,74 \mathrm{~g}_{\text {vaso }}{ }^{-1} \mathrm{com}$ a dose zero de N. O aumento na dose de $\mathrm{N}$ também propiciou redução linear em MST, com o valor máximo de 31,93 g vaso-1

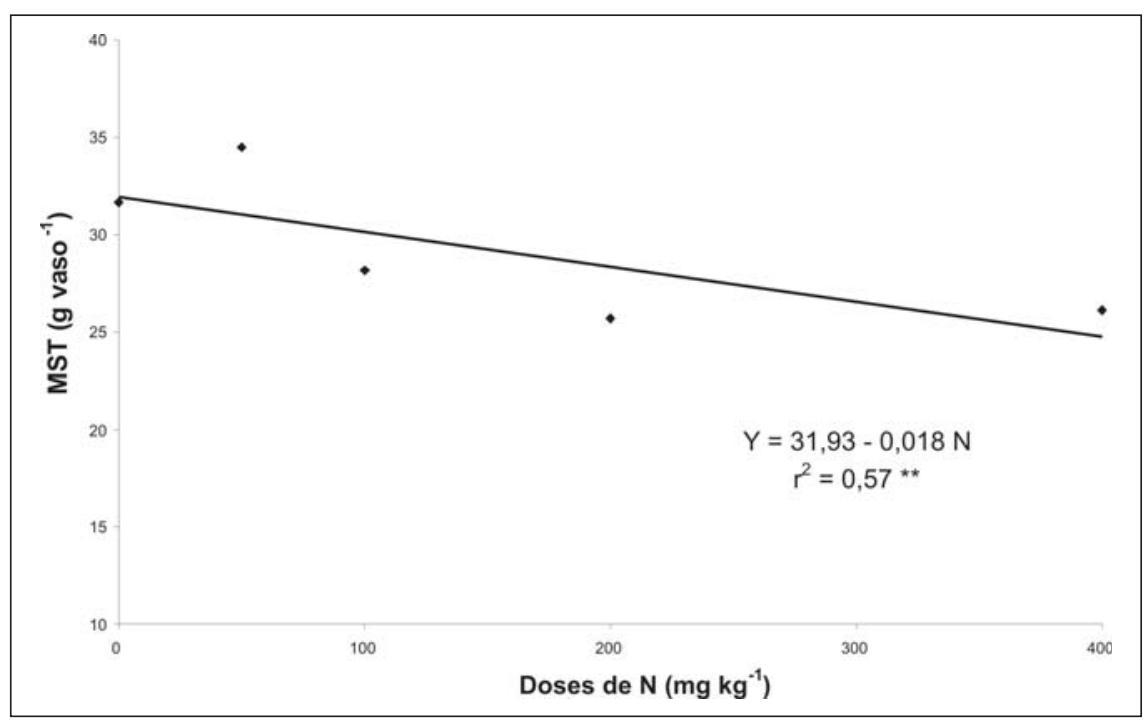

Figura 2. Massa seca total (MST) de planta de batata em função das doses de $\mathrm{N}$ aplicadas ao substrato. Viçosa, UFV, 2004.

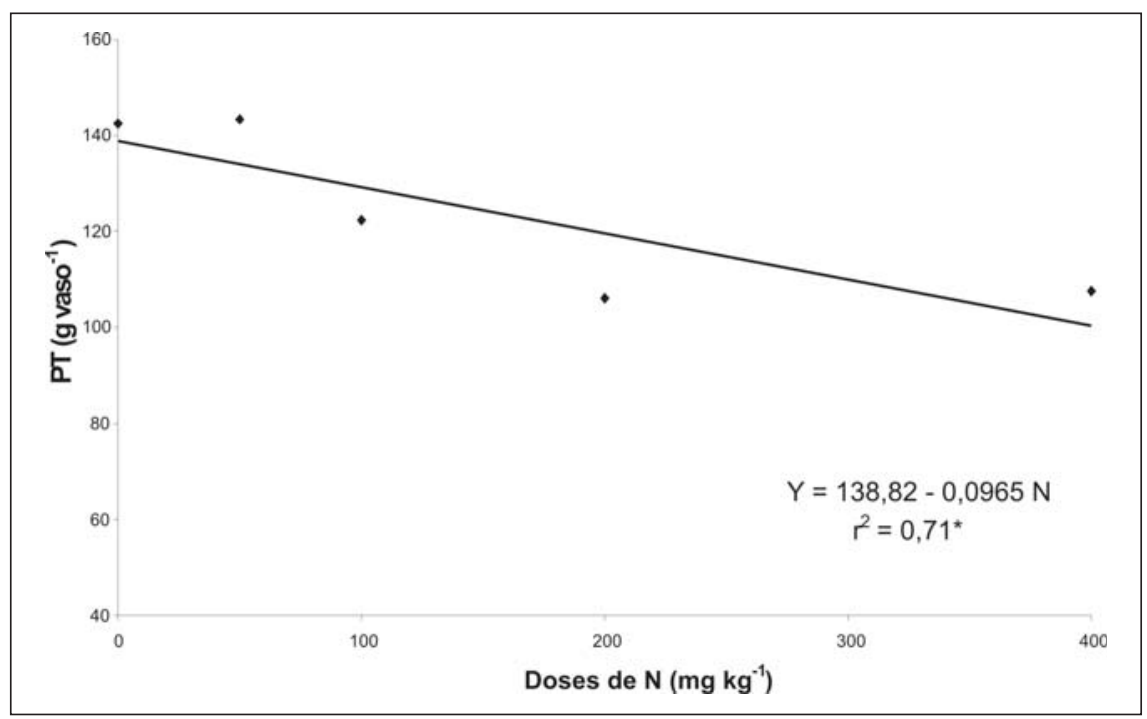

Figura 3. Produção de tubérculos (PT) de batata, em função de doses de nitrogênio no substrato. Viçosa, UFV, 2004.

quando associada à dose zero de $\mathrm{N}$ que propiciou a maior produção de tubérculos (Figura 2). A produção de tubérculos (PT) por vaso foi reduzida linearmente com aumento da dose de $\mathrm{N}$ aplicada ao substrato (Figura 3), sendo obtido o valor máximo de 138,8 g vaso ${ }^{-1}$, sem a adição de $\mathrm{N}$.

Resposta negativa à adição de $\mathrm{N}$ é pouco comum em batata. Isto pode ter sido devido à plântula ter recebido, na micropropagação, quantidade considerável de $\mathrm{N}$ no meio de cultivo, pois o meio proposto por Murashige \& Skoog (1962) contém 60 meq de N. Teixeira \& Pinto (1991), estudando a mini- tuberização da batata em diferentes níveis de $\mathrm{N}$ e sacarose, encontraram que menor dose de $\mathrm{N}$ no meio de cultivo (5 meq de $\mathrm{N}$ ) causou maior produção de mini-tubérculos do que a dose de 60 meq. Adicionalmente, o teor original de $\mathrm{N}$ no substrato pode ter impedido a resposta das plantas à adição de $\mathrm{N}$.

$\mathrm{O} \mathrm{N}$ é fator ambiental envolvido no controle da tuberização que, juntamente com o fotoperíodo, pode permitir a tuberização por meio dos fitohormônios endógenos (Krauss, 1985; Jackson, 1999), sendo que altos níveis de N podem inibir a atividade ou alterar os níveis de reguladores de crescimento 
(Krauss, 1985; Stallknecht, 1985). Em condições de campo, doses consideradas elevadas de $\mathrm{N}$ atrasam a tuberização (Santelith \& Ewing, 1981), reduzem a translocação do carbono da folha para os tubérculos e aumentam o fluxo de $\mathrm{N}$ para as folhas novas ao invés de dirigilo aos tubérculos (Oparka, 1987).

Não houve efeito da dose de N aplicada ao substrato sobre o número de tubérculos por vaso, sendo o valor médio de 9,56. A massa média de cada tubérculo foi 63,2; 33,9; 13,8; 5,4; 2,0; 1,1 e 0,4 g para os tipos de II a VIII, respectivamente. A maior freqüência de tubérculos ficou nos tipos III, IV, V e VI, ou seja, cerca de $79 \%$ do número total de tubérculos produzidos ficaram abaixo do tipo VII e a maior porcentagem, cerca de 37\%, foi do tipo IV.

Não é necessário aplicar nitrogênio ao substrato para a propagação de plântulas de batata advindas de cultivo in vitro.

\section{AGRADECIMENTO}

Ao CNPq pelas bolsas e à FAPEMIG pelo recurso financeiro.

\section{REFERÊNCIAS}

ARGENTA G; SILVA PRF; BORTOLINI CG. 2001. Clorofila na folha como indicador do nível de nitrogênio em cereais. Ciência Rural 31: 715-722.

ASFARY AF; WID A; HARRIS PM. 1983. Growth, mineral nutrition and water use by potato crops. Journal of Agricultural Science 100: 87-101.

ASSIS M. 1999. Novas tecnologias na propagação de batata. Informe Agropecuário 20: 30-33.

BIEMOND H; VOS J. 1992. Effects of nitrogen on the development and growth of the potato plant. 2. The partioning of dry matter, nitrogen and nitrate. Annals of Botany 70: 37-45.

CATALDO DA; HARRON M; SCHRADER LEL; YOUNGS VL. 1975. Rapid colorimetric determination of nitrate in plant tissue by nitration of salicylic acid. Communications in Soil Science and Plant Analysis 6: 71-80.

DANIELS J; SILVAACF; SOUZA ZS; SCHONS J. 2002. Degenerescência de batata-semente básica após um ou dois períodos de cultivo. Horticultura Brasileira 20: 510-513.
DONNELLY DJ; COLEMAN WK; COLEMAN SE. 2003. Potato microtuber production and performance: a review. American Journal Potato Research 80: 103-115.

ERREBHI M; ROSEN CJ; GUPTA SC; BIRONG DE. 1998. Potato yield response and nitrate leaching as influenced by nitrogen management. Agronomy Journal 90: 10-15.

FONTES PCR. 20001. Diagnóstico do estado nutricional das plantas. Viçosa: UFV, $121 \mathrm{p}$.

GIL PT; FONTES PCR; CECON PR; FERREIRA FA. 2002. Índice SPAD para diagnostico do estado nutricional de nitrogênio e para o prognóstico da produtividade da batata. Horticultura Brasileira 20: 611-615.

GIL PT. 2001. Índices e eficiência de utilização de nitrogênio pela batata influenciados por doses de nitrogênio em pré-plantio e em cobertura. Viçosa: UFV, 81p. (tese mestrado).

GRIGORIADOU K; LEVENTAKIS N. 1999. Large scale commercial production of potato minitubers, using in vitro techniques. Potato Research 42: 607-610.

IMA - Instituto Mineiro de Agropecuária Portaria $\mathrm{n}^{\circ}$ 567, de 30 de Janeiro de 2003. 2003. Normas, Padrões e Procedimentos para a Certificação de Material Propagativo de Batata (Solanum tuberosum L.) no Estado de Minas Gerais, Belo Horizonte, 16 p.

JACKSON SD. 1999. Multiple Signaling Pathways Control Tuber Induction in Potato. Plant Physiology 119: 1-8.

KEULEN HV; STOL W. 1991. Quantitative aspects of nitrogen nutrition in crops. Fertilizer Research 27: 151-160.

KRAUSS A. 1985. Interaction of nutrients and tuberization. In: LI PH. Potato Physiology. London, Academic Press, p. 209-230.

LOPES CA; BUSO JA. 1999. A Cultura da Batata. Embrapa Hortaliças. Embrapa Comunicação para Transferência de Tecnologia, Brasília, 184p.

MACLEAN AA. 1981. Time of application of fertilizer nitrogen for potatoes in Atlantic Canadá. American Potato Journal 61: 23-29.

MAKINO A; NAKANO H; MAE T. 1994. Responses of ribulose-1.5- biphosphate carboxylase, cytochrome $f$, and sucrose synthesis enzimes in rice leaves to leaf nitrogen and their relationships to photosynthesis. Plant Physiology 105: 173-179.

MALAVOLTA E; VITTI GC; OLIVEIRA SA. 1997. Avaliação do estado nutricional das plantas: princípios e aplicações. $2^{\mathrm{a}}$ edição. Piracicaba: Associação Brasileira para Pesquisa da Potassa e do Fosfato, 319 p.

MALDONADO LA; JE WRITH JE; SCOTT GJ. 1998. Constraints to potato production and use of potato in Asia. American Journal of Potato Research 75: 71-73.

MEYER RD; MARCUM DV. 1998. Potato yield, petiole nitrogen, and soil nitrogen response to water and nitrogen. Agronomy Journal 90: 420-429.
MINOTTI PL; HALSETH DE; SIECZKA JB. 1994. Field chlorophyll measurements to assess the nitrogen status of potato varieties. HortScience 29: 1497-1500.

MURASHIGE T; SKOOG F. 1962. A revised medium for rapid growth and bio assays with tobacco tissue cultures. Physiologia Plantarum 15: 473-479.

NAGANO Y. 1999. Batata brasileira tem qualidade. Informe Agropecuário 20: 1-2.

OLIVEIRA CA. 2000. Potato crop growth as affected by nitrogen and plant density. Pesquisa Agropecuária Brasileira 35: 939950.

OPARKA KJ; DAVIES HV; PRIOR DAM. 1987. The influence of applied $\mathrm{N}$ on export and partitioning of current assimilate by fieldgrown potato plants. Annals of Botany 59: 484488.

PIEKIELEK WP; FOX RH. 1992. Use of $\mathrm{s}$ chlorophyll meter to predict sidress $\mathrm{N}$ requeriments for maize. Agronomy Journal 84: 59-65.

PORTER GA; SISSON JA. 1991. Petiole nitrate content of Maine - grown Russet Burbank and Shepody potatoes in response to varying nitrogen rate. American Potato Journal 68: 493-505.

PORTER GA; SISSON JA. 1993. Yield, marked quality and petiole nitrate concentration of non-irrigated Russed Burbank and Shepody potatoes in response to sededressed nitrogen. American Potato Journal 70: 101-116.

ROBERTS S; WEAVER WH; PHELPS JP. 1982. Effect of rate and time of fertilization on nitrogen and yield of Russet Burbank potatoes under center pivot irrigation. American Potato Journal 59: 77-86.

RODRIGUES FA; FONTES PCR; PEREIRA PRG; MARTINEZ HEP. 2000. Nível critico do índice spad na folha da batateira, em solução nutritiva. Horticultura Brasileira 18: 766-767.

STALLKNECHT GF. 1985. Tuber initiation in Solanum tuberosum: effect of phytohormones and induced changes in nucleic acid and protein metabolism. In: LI PH. Potato Physiology. London, Academic Press, p. 231260.

TEIXEIRA DMC; PINTO JEBP. 1991. Minituberizaçao da batata em diferentes níveis de N, sacarose e BAP. Revista Brasileira de Fisiologia Vegetal 3: 77-81.

VOS J; BOM M. 1993. Hand-held chlorophyll meter: a promising tool to asses the nitrogen status of potato foliage. Potato Research 36: 301-308.

VOS J; VAN DER PUTTEN. 1998. Effect of nitrogen supply on leaf growth, leaf nitrogen economy and photosynthetic capacity in potato. Field Crops Research 59: 63-72.

WHITE RP; SANDERSON JB. 1983. Effect of planting date, nitrogen rate, and plant spacing on potatoes grown for processing in Prince Edward Island. American Potato Journal 60: 115-126. 